\title{
THE HISTORY OF BUNDLE BRANCH BLOCK
}

\author{
by
}

ARTHUR HOLLMAN*

It did not require graphic methods of registering the heartbeat to find that ventricular contraction followed atrial contraction, or to discover abnormalities of this process. William Harvey observed prolongation of the interval between atrial and ventricular contraction and also demonstrated that ventricular contraction might occur in the dying heart only after several atrial beats-both being clear examples of atrio-ventricular block. Even after W. His jun. had demonstrated the anatomy of the atrio-ventricular bundle in 1893, he relied on visual observation in experiments two years later to show that destruction of this bundle led to atrio-ventricular block. ${ }^{1}$ The comparatively slow conduction time from atria to ventricles allowed these observations to be made. But the best experimental proof of the normal dependence of ventricular upon atrial contraction came in 1905 from Erlanger. ${ }^{2}$ Using mechanical recording, he showed that, in experimental animals, he could produce either partial or complete heart block by varying the pressure on the bundle of His with a special clamp. He also demonstrated that in these animals there was histological evidence of damage to the bundle.

When, however, the impulse travels through the bundle of His and its branches the conduction velocity is much faster than that between atria and ventricles, and only electrical records can show this activity and especially its abnormalities. Figure 1 shows the human electrocardiograms of left and right bundle branch block (BBB). This unique ability of the electrocardiogram (ECG) to record abnormalities in ventricular excitation must have caused great excitement among the early workers, accustomed as they were to being able to analyse only arrhythmias with mechanical devices such as Mackenzie's polygraph. In fact, using mechanical recording in 1909, Barker and Hirschfelder ${ }^{3}$ investigated the idea originally proposed by von Leyden ${ }^{4}$ in 1868 that contraction might occur of one ventricle alone. They attempted experimentally to divide a branch of the His bundle. Having failed with a knife introduced via the carotid artery and aorta, they then employed a $3 \mathrm{~mm}$ knife

*Arthur Hollman, MD, FRCP, FLS, Cardiac Department, University College Hospital, London WC1E 6AU.

\footnotetext{
${ }^{1}$ Wilhelm His jun, Zbl. Physiol., 1985, 9: 496.

2 J. Erlanger, 'Vorläufige Mitteilung über die Physiologie des Herzblocks Säugetieren', ibid., 1905. 19: 9-13.

${ }^{3}$ Lewellys F. Barker and A.D. Hirschfelder, 'The effects of cutting the branch of the His bundle going to the left ventricle', Arch. int. Med., 1909, 4: 193-200. 365 .

'E. von Leyden, 'Ueber ungleichzeitige Kontraction beider Ventrikel', Arch. path. Anat., 1868, 14:
} 

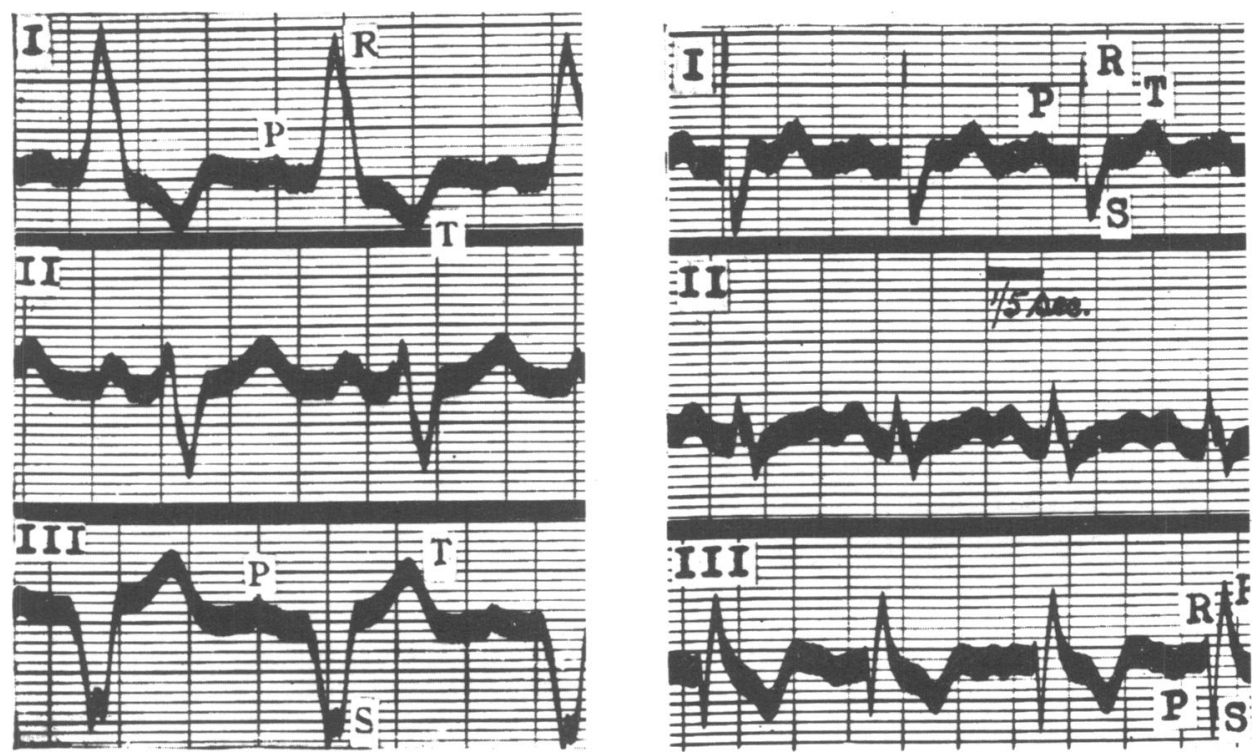

Figure 1. Human electrocardiograms in the three limb leads showing LBBB on left, and RBBB on right. Note the broad S wave in lead I with RBBB. Reproduced with permission from William Evans, Cardiography, London, Butterworth, 1948.

introduced through the wall of the left ventricle and, in one dog as evidenced by histology, they succeeded in cutting the left branch (in the others complete heart block ensued). They showed that contraction of both ventricles was unimpaired by this division and concluded "that the His bundle plays little if any role in the co-ordination of the ventricles". This conclusion was disputed, but in fact they were demonstrating, quite correctly, that "there is a muscular bridge between the two chambers and no such narrow connection as is present between atria and ventricles".

During the early phase of electrocardiographic work in the human being, traces were produced which indicated that there were different patterns of ventricular contraction. In 1914, using Einthoven's string galvanometer, Lewis and Cohn noted in one patient ${ }^{5}$ that "unusual curves were obtained, which permitted the suggestion that even though no injury to the main stem of the conduction system was present, a defect in conduction from the auricles to a single ventricle existed, due possibly to a lesion of the bundle branch to this ventricle or to one of its subdivisions". Other workers had made similar observations earlier. Prior to his invention of the string galvanometer in 1903, Einthoven had extended the work of Burdon Sanderson and Page $^{6}$ who, in 1883, had recorded for the first time the electrical activity of the heart, from a frog, by using the capillary electrometer of W. Lippmann. In 1894, Einthoven had recorded with this electrometer a human ECG showing a wide QRS complex and, remarkably, was able to obtain an almost identical tracing on the same patient

\footnotetext{
'Alfred E. Cohn and Thomas Lewis, 'The pathology of bundle branch lesions of the heart', Proc. N. Y. Path. Soc., 1914. 14: 207-216.

' J. Burdon Sanderson and F.J.M. Page, 'On the time relations of the excitatory process in the ventricle of the heart of a frog', J. Physiol., 1880, 2: 384.
} 


\section{A. Hollman}

using the galvanometer thirty-one years later. Both of these records were published in his Nobel Lecture of $1924 .^{7}$ By this time, they could be used as an example of "blocking of conduction in the left branch of the bundle of His" (fig. 2).
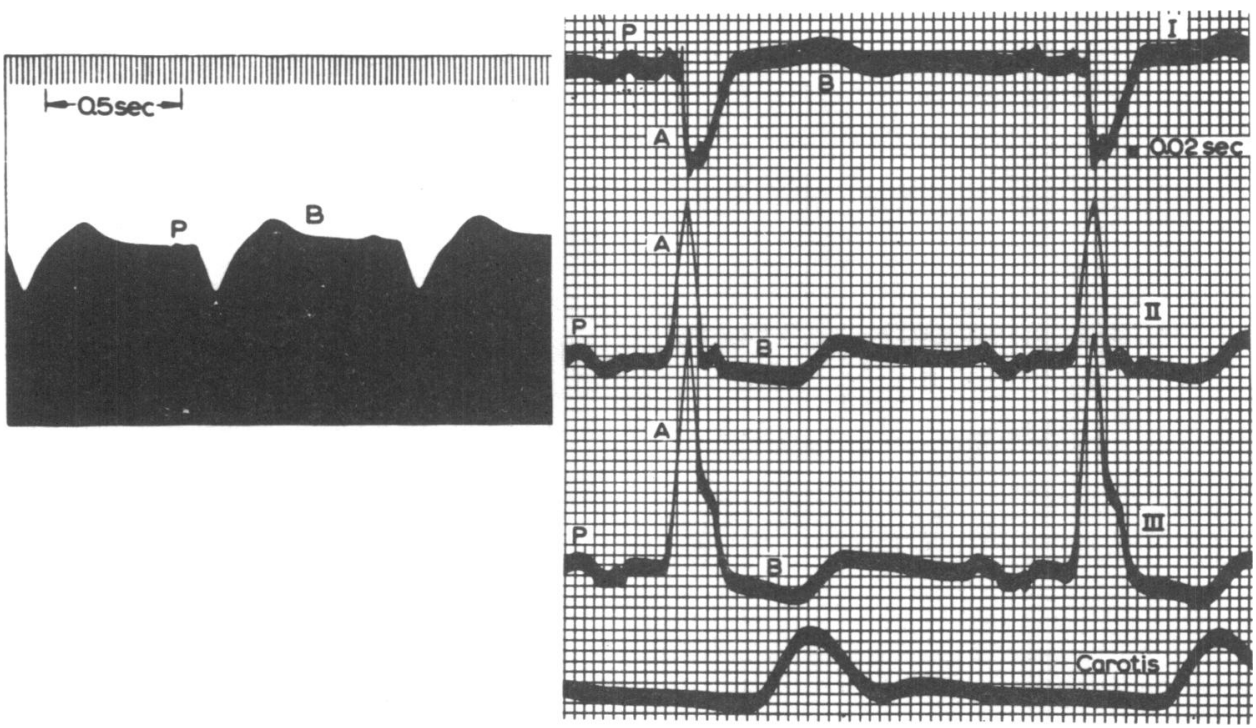

Figure 2. Electrocardiograms from the same patient taken by Einthoven, (left) in 1894 with capillary electrometer (lead I), and (right) in 1925 with a string galvanometer (leads I,II, and III and arteriogram). (From Einthoven op. cit., footnote 7.)

The functional proof of Tawara's anatomical demonstration in $1906^{8}$ that the branches of the His bundle conveyed the impulses to the ventricles was given experimentally in 1910 by Eppinger and Rothberger, ${ }^{9}$ who showed that cutting both of the branches led to complete heart block. In a previous paper in $1909,{ }^{10}$ these authors had recorded the serial ECG changes in a dog resulting from the injection of silver nitrate into the septum and the ventricles. They used a single unnamed lead, and in addition to producing a marked current of injury pattern, they demonstrated complexes with a wide QRS duration (fig. 3). This can now be interpreted as the result of bundle branch lesions, although they did not actually say so. The complexes were more or less opposite in pattern with right- and left-sided injections, and this was the earliest experimental demonstration of bundle branch block. Next, in their 1910 paper they used a single lead from oesophagus to anus and showed that surgical section of one or other bundle branch produced a wide QRS complex that was

\footnotetext{
${ }^{7}$ Willem Einthoven (Nobel Lecture, 1925), 'The string galvanometer and the measurement of the action currents of the heart', Nobel Lectures: Physiology or Medicine, 1922-41, Amsterdam, Elsevier, 1965. p.110.

S. Tawara, Das Reizleitungssystem des Säugetierherzens, Jena, 1906.

${ }^{9}$ H. Eppinger and C.J. Rothberger, 'Ueber die Folgen der Durchschneidung der Tawaraschen Schenkel des Reizleitungssytems', Zt. klin. Med., 1910, 70: 1-20.

${ }^{10} \mathrm{H}$. Eppinger and C.J. Rothberger, 'Zur Analyse des Electrokardiogramms', Wien. klin. Wschr., 1909, 22: 1091-1098.
} 


\section{The history of bundle branch block}

oppositely directed according to which side was cut. In the light of this result they realized that they had demonstrated bundle branch block in their 1909 paper.

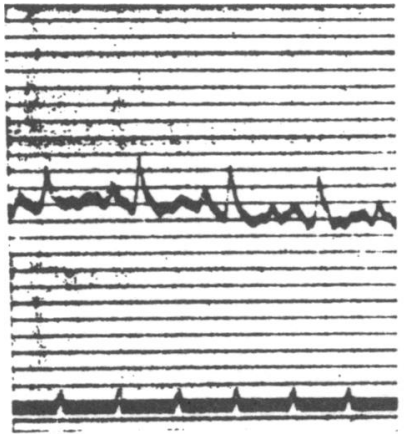

a

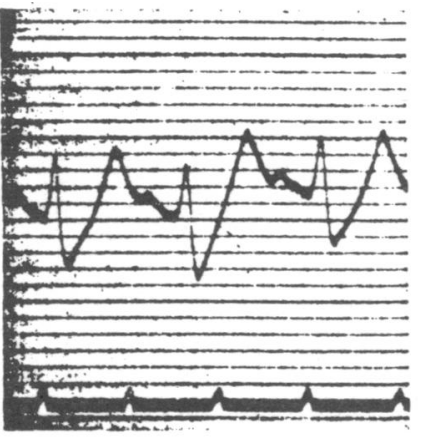

b

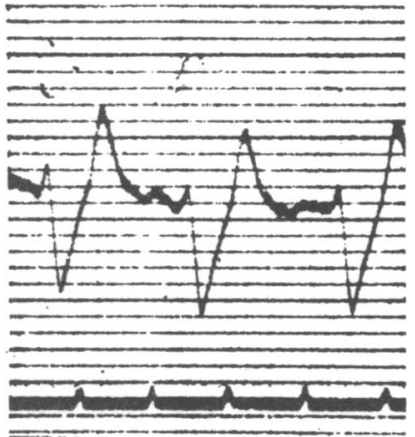

Figure 3. The first electrocardiograms in experimental bundle branch block: (a) control; (b and c) after injection of silver nitrate into the right ventricle. (From Eppinger and Rothberger, op. cit., footnote 10.)
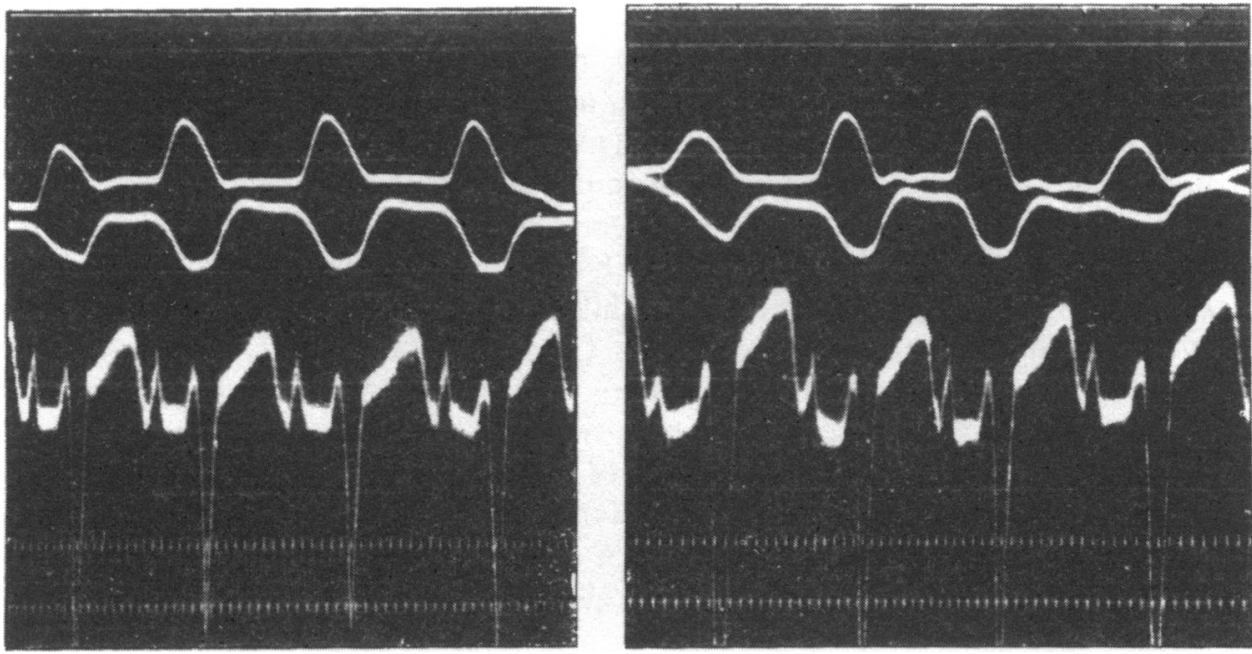

Figure 4. RBBB in dog showing deep $S$ waves in lead I (on left) and in the ano-oesophageal lead (on right). (From Rothberger and Winterberg, op. cit., footnote 11.)

Rothberger and Winterberg ${ }^{11}$ repeated the work in the dog using, in addition, lead I. They showed a deep negative deflection in this lead with RBBB (fig. 4) and an upright notched complex with LBBB. They also showed that the ano-oesophageal lead resembled lead III, and stated that bundle branch block in the human being should not be diagnosed unless both lead I and lead III were available, otherwise,

${ }^{11}$ C.J. Rothberger and $\mathrm{H}$. Winterberg, 'Zur Diagnose der einseitigen Blockierung der Reizleitung in den Tawaraschen Schenkeln', Zbl. Herz. Gefasskrankh., 1913: 5: 206-208. 


\section{A. Hollman}

they said, one might be unable to make the differential diagnosis with ventricular hypertrophy. A similar point, in a related context, had been made by Einthoven, ${ }^{12}$ who was the first to attempt the localization of the site of origin of ventricular premature contractions by studying the direction of the deflections in relation to the three axial leads.He employed lead I to distinguish between the right and left sides and the other two leads to differentiate proximity of the point of origin to base or apex.

In 1912, Lewis ${ }^{13}$ had a patient with paroxysmal tachycardia in whom numerous premature atrial contractions were present outside the paroxysms. When the premature atrial complex (the $P$ wave) was uniform, the succeeeding ventricular contraction might be of a normal or a divergent type. Lewis suggested that, if divergent, it might be due to damage affecting a special branch of the arborization of the bundle. He proposed the term "aberration of the supraventricular impulse" to describe these complexes, and later, in the context of human and experimental bundle branch block, he said: "I term the resultant beats aberrant, for they are caused by impulses which have gone astray". ${ }^{14}$ Around 1915 , Lewis ${ }^{15}$ proceeded to repeat and extend the previous experimental work on the production of bundle branch block in order to elucidate what exactly were the ECG changes in human beings with this condition. His technique initially consisted of introducing a special form of clamp-somewhat like an artery forcep-into the ventricles and squeezing the septum stepwise until the typical ECG tracing was obtained. But being unable histologically to be certain what lesions he was producing by this means, he changed to actually cutting the branches with a small tenotomy knife, following the method of Eppinger and Rothberger, although the clamp technique had an advantage in that "it is possible in one and the same animal to obtain the curves corresponding to right and left bundle branch lesions by alternately compressing these branches". The electrocardiograph leads employed were Einthoven's limb leads, I, II, and III. Lewis showed that an abnormal ECG with a wide QRS complex regularly develops when the corresponding bundle division is cut across and that the change persists unless the lesion is partial, in which case the abnormality is transient, a point he illustrated very neatly by an example where the right division was temporarily blocked by a tiny haemorrhage into its sheath. Division of the right branch gave deep negative complexes in II and III (fig. 5), whilst that of the left branch gave large positive complexes in these leads (fig. 6.). In both instances, lead I could be similar with a wide notched positive $Q R S$ complex with an inverted $T$ wave, but with the difference that the $Q$ wave remained with right but not with left block. But in two of the three published ECGs with RBBB there was a prominent broad S wave in lead I. His conclusion that the $Q$ wave due to activation of the septum from the left bundle

\footnotetext{
12 Willem Einthoven, 'Weiteres ueber das Elecktrokardiogramm', Pflügers Arch. ges. Physiol., 1908, 122: 579.

${ }^{13}$ Thomas Lewis, 'Observations upon disorders of the heart's action', Heart, 1912, 3: 279-300.

14 Thomas Lewis, The mechanism and graphic registration of the heart beat, 3rd ed., London, Shaw, 1925 , p. 127.

${ }^{15}$ Thomas Lewis, 'The spread of the excitatory process in the vertebrate heart', Phil. Trans. R. Soc. Lond., series B, 1916, 207: 221-310.
} 

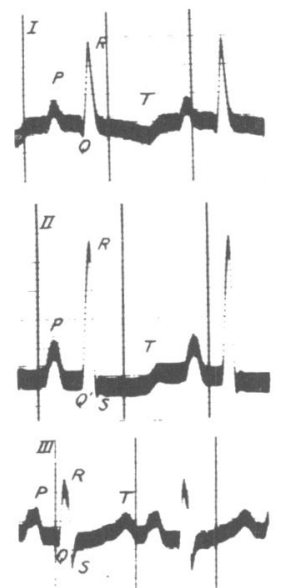

FI: 15
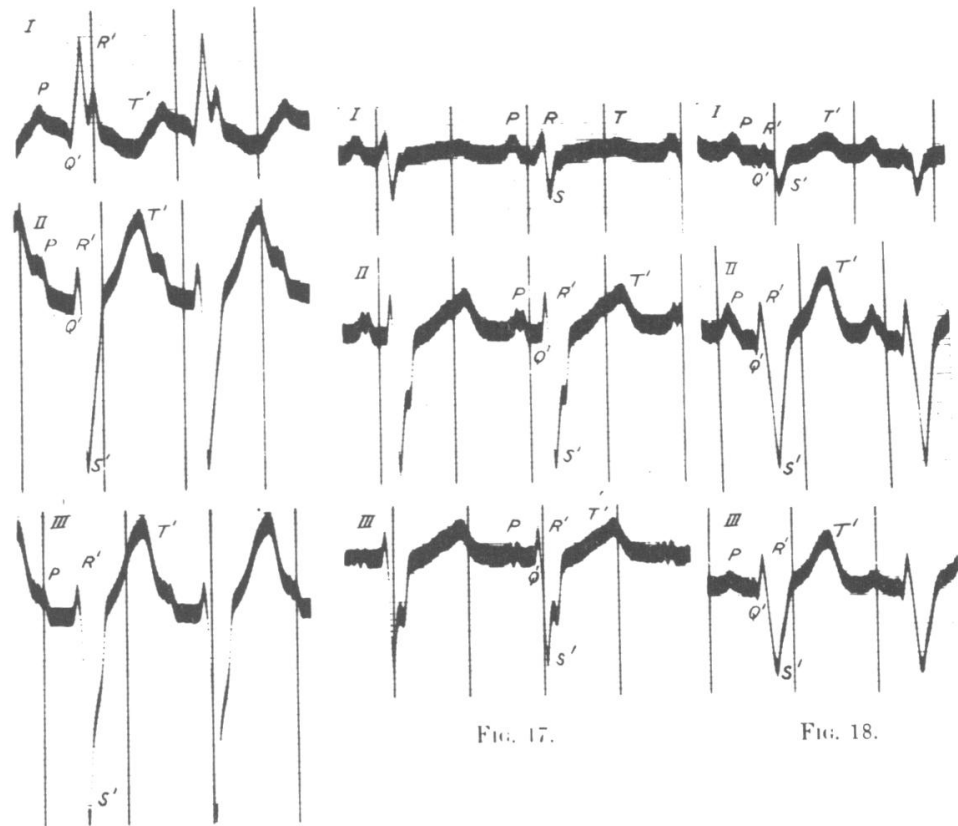

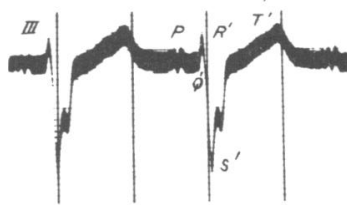

Fin: 1T.

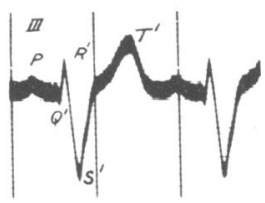

FII: 18.

Fili. 16 .

Figure 5. RBBB in dog. Control in dog 1, Fig. 15. BBB in dogs 1,2 and 3 , figs, 16, 17, 18. Note the deep negativity in leads II and III closely resembling the pattern in human LBBB. However, unlike the human pattern, the $Q$ wave is preserved in lead $I$, which also in dogs 2 and 3 shows the broad $S$ wave typical of RBBB. (From Lewis, op. cit., footnote 15.)
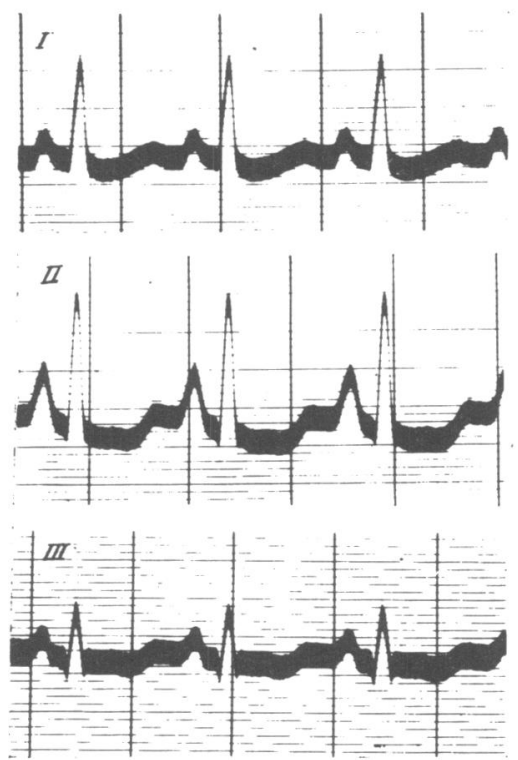

FIG. 19.
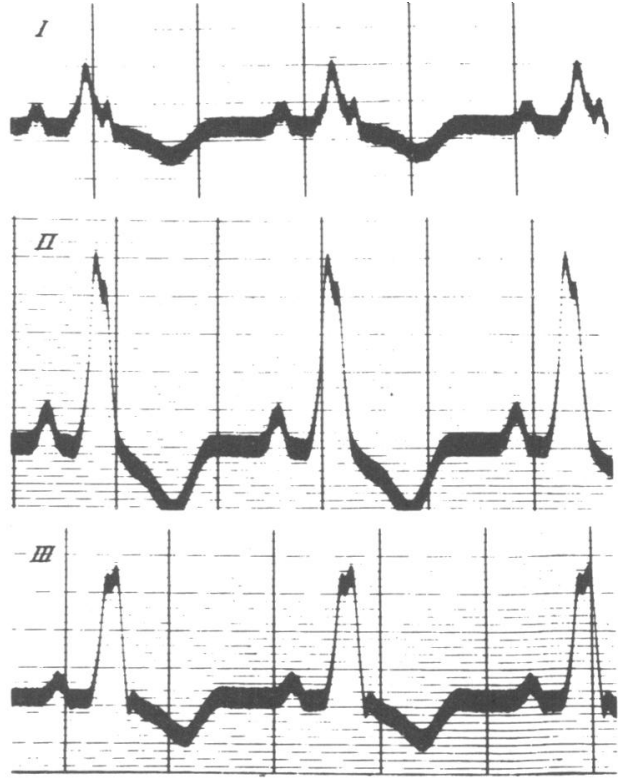

FIG. 20.

Figure 6. LBBB in dog. Control Fig. 19, BBB Fig. 20. Lead I with no $Q$ wave resembles the human pattern, but the tall $R$ waves in II and III do not, (From Lewis, op. cit., footnote 15.) 


\section{A. Hollman}

division was based also on the findings in other experiments ${ }^{16}$ that the earliest intrinisic deflection was found from the septum beneath the aortic valves, that the corresponding electrical axis was directed from left to right, and that $Q$ is absent in the toad and tortoise which have no septum. Because the preliminary deflections produced by division of the left branch were confined to activation of the right ventricle, he called this a dextrocardiogram whilst a right-sided lesion produced a levocardiogram. By the use of his twin-string galvanometer, Lewis was able to record a standard curve with the one under study and thus to align precisely in time one tracing with another. He then meticulously plotted the spread of the deflections produced by ventricular activation and by algebraic addition of the dextrocardiogram and levocardiogram calculated the bicardiogram and showed it to be identical with the natural ECG, thus proving that this is the summated effects of right and left ventricular activity. His final analysis of the effect of bundle branch division in the dog was to calculate from his re-plotted dextro- and levocardiograms the changes in the electrical axis of the heart. Division of the right bundle led the axis to deviate to the left whilst left block caused right axis deviation (figs. 7 and 8).

The next stage was to examine curves from human subjects with broad QRS deflections in the light of the animal experiments. The curves fell into two main types-those with a tall R wave in lead I and a deep S in III and those with the opposite configuration. The recordings were analysed like those from the dog by re-plotting the deflections in simultaneously arranged leads and then creating. a pattern of the electrical axis. The results (fig. 9) in the commonly encountered human type showed the deep $S$ wave in III and the left axis deviation, which were known to be produced in the dog by dividing the right branch. Apart from the absence of a $Q$ wave in lead $I$ in man the curves certainly are similar. This must have been the decisive influence which led Lewis to label this common type as right bundle branch block because comparison of the dog and human curves from the other, uncommon, type showed an obvious difference. This difference lies in the presence of a broad $\mathrm{S}$ wave in lead I in the human curve and its absence in the dog curve. When summarizing his work in The mechanism and graphic registration of the heart beat (3rd ed., 1925), ${ }^{17}$ Lewis showed an ECG from dog right branch block without an S wave in lead I, but in his original paper this figure is followed by two others which show a prominent and broad SI (see fig. 5). We shall see later that other work in the dog also showed a broad S wave in lead I with right branch block.

It was doubt about these changes in lead I, which Rothberger and Winterberg had also noted, that led Lewis to experiment on a monkey, presumably in the light of his own comment: "At this point I would utter the warning that the curves just described are those recorded from dogs: in their broad features the corresponding human curves resemble them; but the human curves, especially those which correspond to lesions of the left division, differ from them in detail". He used a monkey partly because, in that animal, there are no strands of Purkinje substance bridging the cavity of the right ventricle. One large Rhesus monkey was operated on and, surprisingly,

\footnotetext{
${ }^{16}$ Thomas Lewis, 'The origin of the deflections $Q, R$ and $S$, in axial electro-cardiograms of the dog', $J$. Physiol., 1915, 49: 49-50.

${ }^{17}$ Lewis, op. cit., note 14 above, p. 79.
} 


\section{The history of bundle branch block}

Lewis, divided the right not the left branch and calculated the dextrocardiogram from the levocardiogram and bicardiogram. The calculated result does resemble the human curve, but the Rhesus monkey's normal ECG is certainly dissimilar from a human one. The monkey work, in other words, confirmed the extrapolation made from the dog.
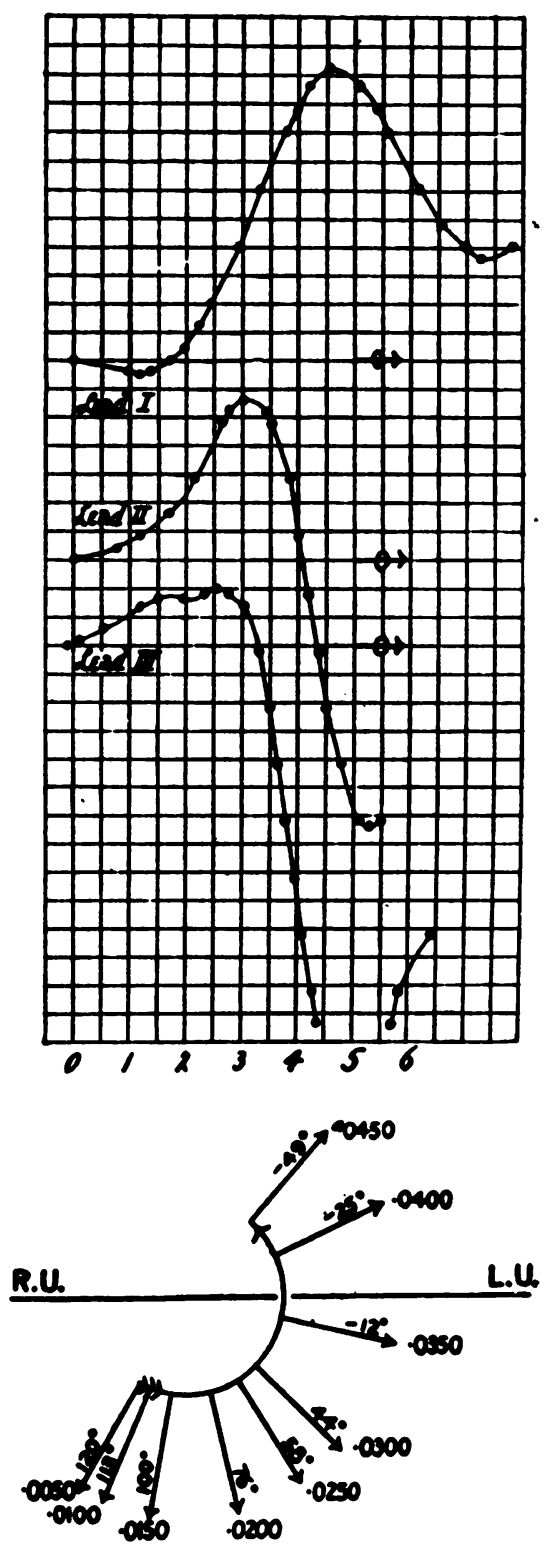

Figure 7. RBBB in dog, the levogram. Above: ECG redrawn up to 0.06 seconds. Below; diagram of electrical axes showing anti-clockwise rotation to the left. (From Lewis, op. cit., footnote 15.) 


\section{A. Hollman}
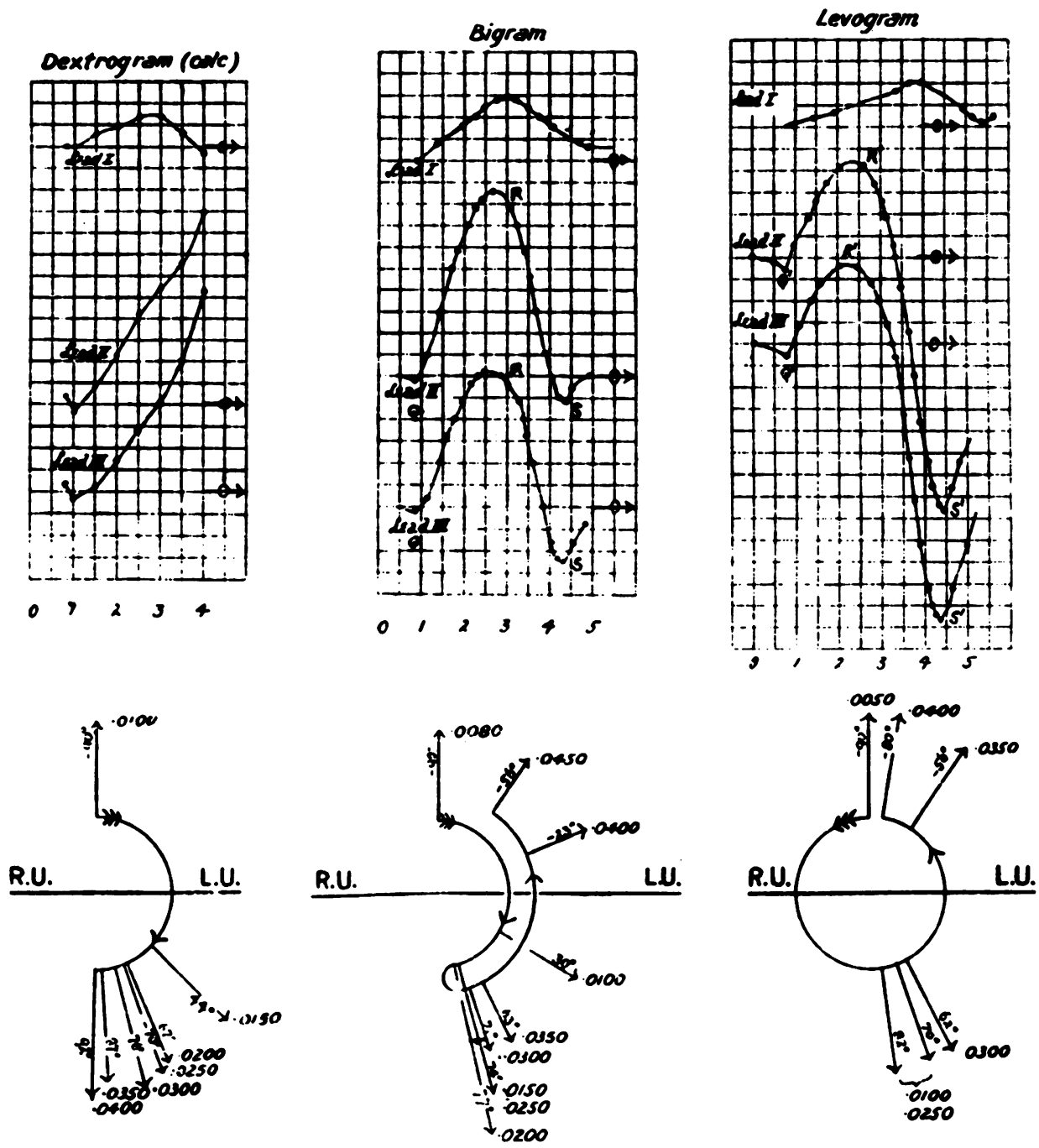

Figure 8. BBB in dog showing redrawn ECGs and electrical axes for an intact heart (bigram) RBBB (levogram) and calculated LBBB (dextrogram). The axis is clockwise and to the right with LBBB. (From Lewis, op. cit., footnote 15.) 

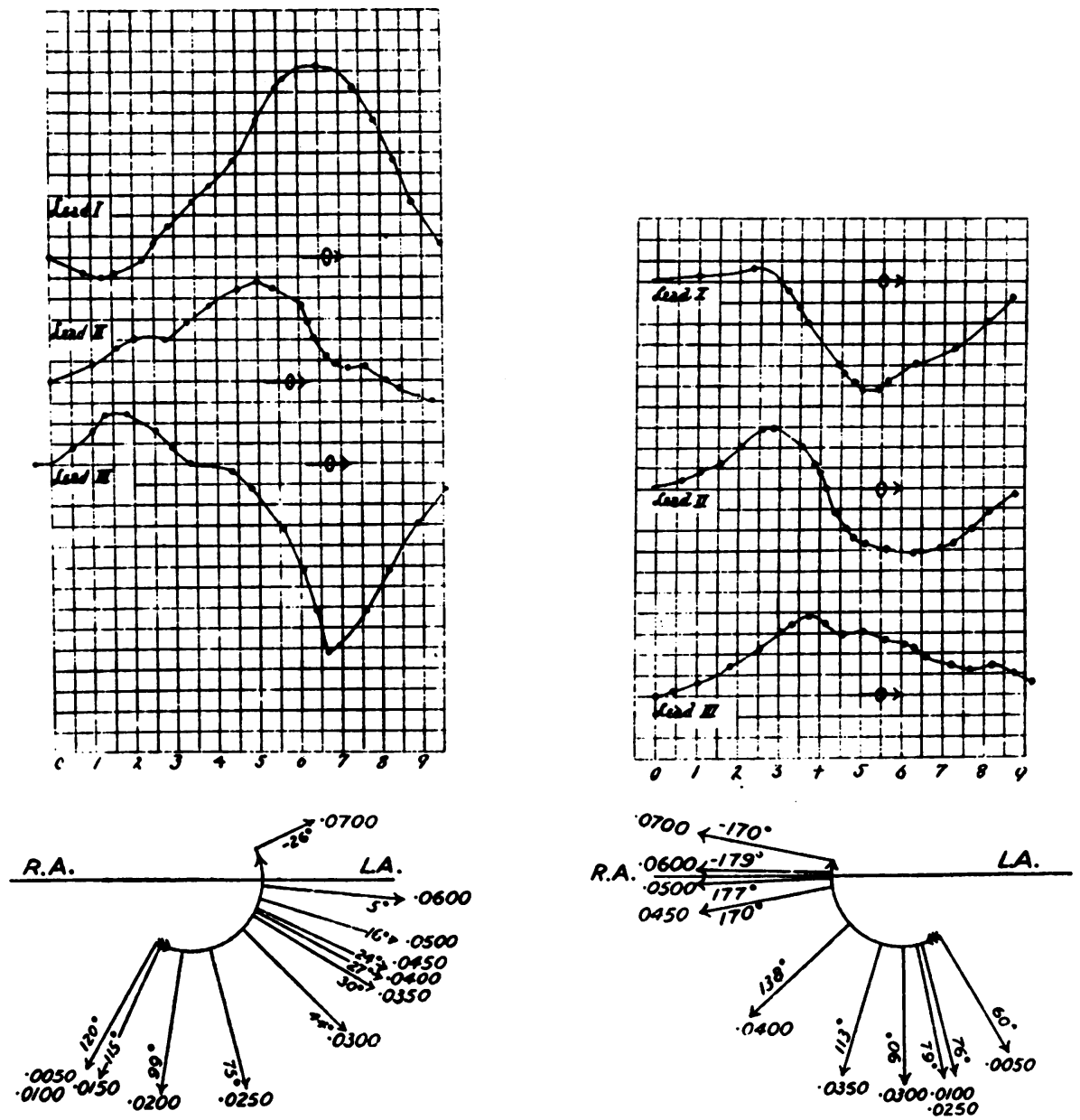

Figure 9. BBB in human. Redrawn ECGs and electrical axes for (on left) what Lewis called right block, showing leftward movement of the axis, and (on right) left block showing rightward movement. (From Lewis, op. cit., footnote 15.)

An obvious parallel study in man to the experimental production of block in animals was the correlation of the electrocardiographic changes with the gross and microscopic anatomy of the conducting tissues at post mortem. Eppinger and Stoerk in $1910^{18}$ were the first to do this, and their findings confirmed the erroneous conclusions drawn from the animal work. They had two patients in whom this correlation was made. The first case was a man of thirty-five with aortic regurgitation and stenosis, in bi-ventricular failure. To us, the ECG shows left bundle branch block, but it was interpreted by them, from the animal work, as "resembling the picture of a dissection of the right Tawara bundle". Microscopic examination revealed sclerosing scar tissue in the septum. A continous series of sections of the His

\footnotetext{
${ }^{18}$ H. Eppinger and O. Stoerk, 'Zur Klink des Electrokardiogramms', Zt. klin. Med., 1910, 71: $157-164$.
} 


\section{A. Hollman}

bundle showed no abnormality, but in the area where one would expect to see the division of Tawara bundles, the Tawara bundle (and the right was obviously implied here) was displaced by fibrous tissue. The left bundle was examined and no pathology found. The second case was a woman of thirty-seven, who died during a nocturnal attack of angina and dyspnoea. Her ECG (fig. 10) shows what we would describe as left branch block. Pathologically, her heart showed coronary arteriosclerosis with severe hypertrophy and dilatation of the left ventricle. The septum had a scar extending from the aortic valve towards the right. An area of the septum membranaceum was discoloured white, particularly on the right side where the changes reached the mid-anterior tricuspid tail. Histology showed that the right Tawara bundle entered the myocardial scarring and was replaced by it for a long section. The left bundle was free. These findings fitted perfectly with the animal work, and one can well understand how it must have seemed undeniable proof as to the side of the bundle branch block in man. One should note that Lewis and others thought that if the left branch was blocked, then it must be blocked near its origin, because its branches fanned out so widely afterwards that it was assumed that interruption of all branches would be impossible. But they were extrapolating from the healthy animal heart where, indeed, a very wide cut would have been necessary to divide all the branches. But in pathological conditions in man widespread fibrosis of the branches is not only possible but common. Lewis had four patients with what we now regard as left branch block but which were, to him, right branch block. Their hearts were examined by Cohn ${ }^{5}$ as part of a series of hearts which had been dissected for the purpose of studying ventricular hypertrophy. Cohn said that the specimens were unsuitable for a proper analysis of the bundle branches because they consisted only of the septum, which tapered towards the apex. Even so, two hearts showed atrophy of fibrils at the centre of the fibres of the left branch and the other two a marked increase in connective tissue in the septum confined to or more extensive on the left and "in close proximity to the left branch of the A-V bundle". No lesions of the right bundle were found. Lewis later wrote to the effect that the expected lesions were not found. It is difficult to avoid the conclusion that he ignored Cohn's study, which suggested that the problem actually was on the left side, because he had already decided from his dog work and from Eppinger and Stoerk's paper that these patients must have had right branch block.

One other earlier post-mortem case, again by Cohn and Lewis, ${ }^{19}$ should be mentioned because the electrocardiogram was illustrated and presumably confirmed Lewis's interpretation. The patient was a man of seventy-seven with Adams-Stokes attacks and complete heart block. His heart showed old inflammatory lesions which seriously compromised but did not completely divide the main stem and right branch of the A-V bundle. The electrocardiogram (fig. 11) showed strong left axis deviation-like that in the dog with right branch block. We now know that this would have been caused by fibrosis of the branches of the left bundle, and they were not examined. What it does show very well is the broad S wave in lead I which is so characteristic of RBBB.

${ }^{19}$ Alfred E. Cohn and Thomas Lewis. 'A description of a case of complete heart-block, including the post-mortem examination', Heart, 1913, 4: 7-14. 


\section{The history of bundle branch block}

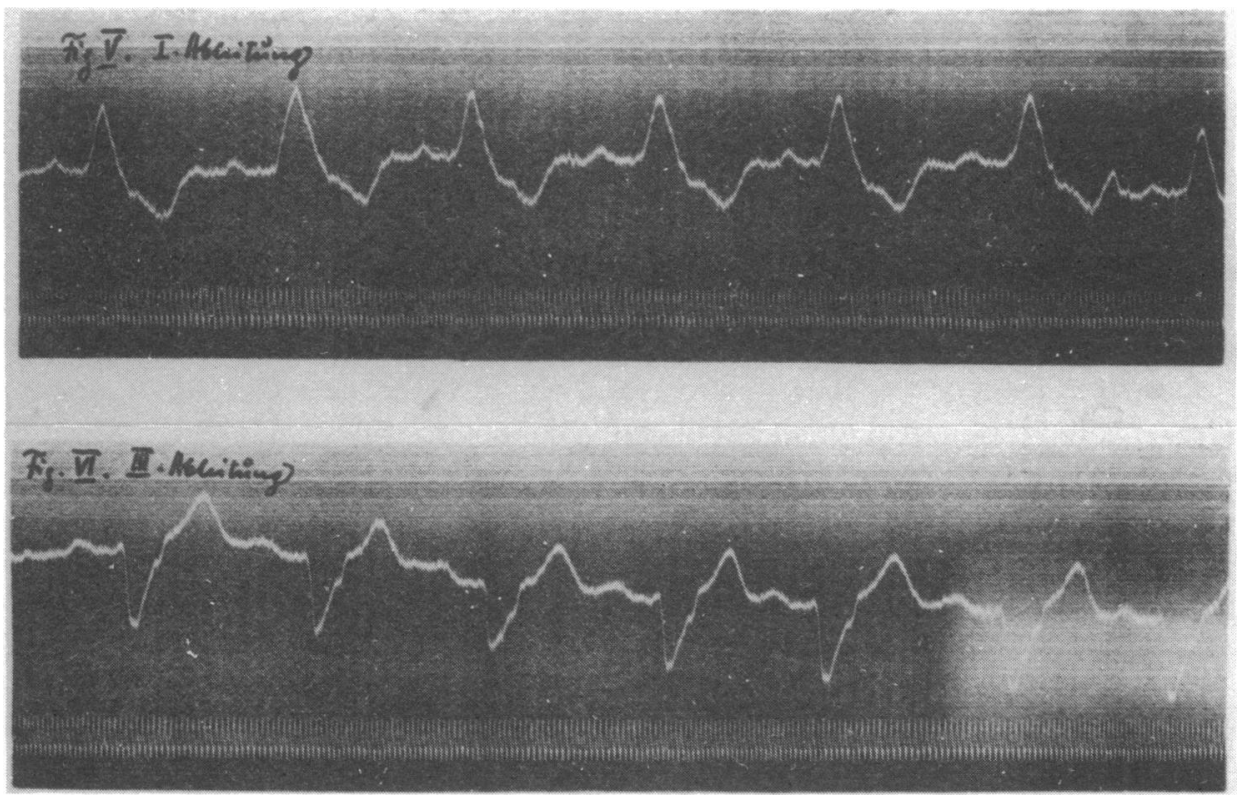

Figure 10. Leads I and III and from Case 2 of Eppinger and Stoerk (op. cit., footnote 18) showing LBBB. But their histology showed a lesion only in the right bundle and it was this case that played an important part in the misnaming of BBB.

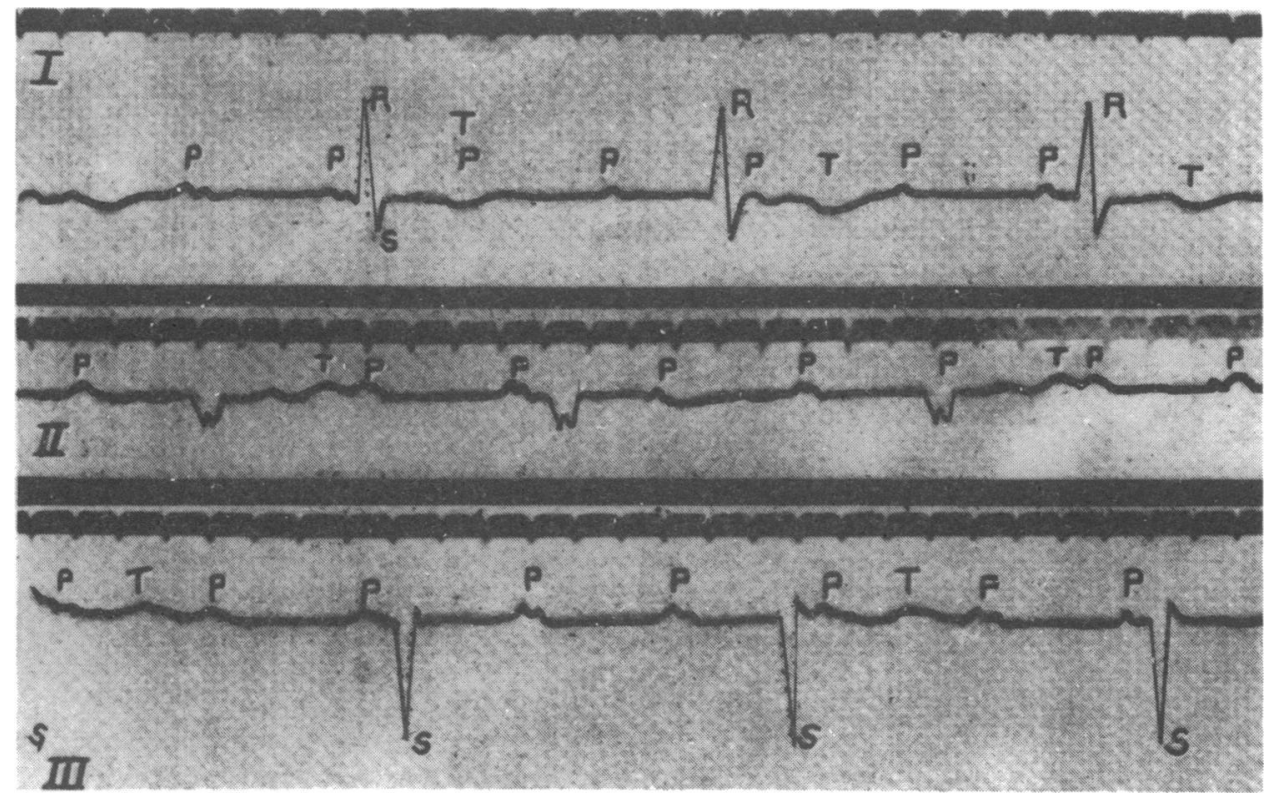

Figure 11. The case of Cohn and Lewis (op. cit., footnote 19) with a right branch lesion on histology. The ECG shows left axis deviation. It also shows the broad S wave in lead I typical of RBBB. Complete heart block is present. 


\section{A. Hollman}

A later study by Oppenheimer and Pardee (1920), ${ }^{20}$ which contradicted Lewis's account, was not quoted by him in his 1925 bibliography. They examined the hearts in two cases of BBB. In the one with what was then called RBBB, they found the left bundle branch to be embedded in dense fibrous tissue throughout its course with septal endocardial thickening on the left but not on the right. In the other with "LBBB", the right bundle branch was almost completely interrupted over a $4 \mathrm{~cm}$. length, whilst the left branch was normal. They cautiously concluded that if their results were repeatedly confirmed by others, then "the usually accepted ECG interpretation of right and left bundle branch block may have to be revised".

The final comparison that Lewis made was also the one that was the most damaging to his classification of bundle branch nomenclature. He took ECGs which showed left ventricular and right ventricular hypertrophy and mounted them side by side with similar looking tracings from patients with bundle branch block. So he then had an ECG with left ventricular hypertrophy paired with what he regarded, from animal comparison, as right bundle branch block and vice versa. Another example (fig. 12) is even more striking because in the same patient with aortic disease he showed tracings taken within two days of each other, one showing (to him) right bundle branch block and the other left ventricular preponderance.

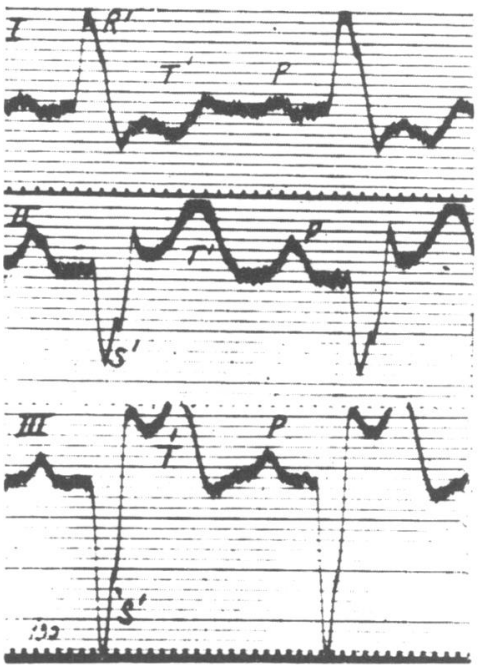

Fig. 89 .

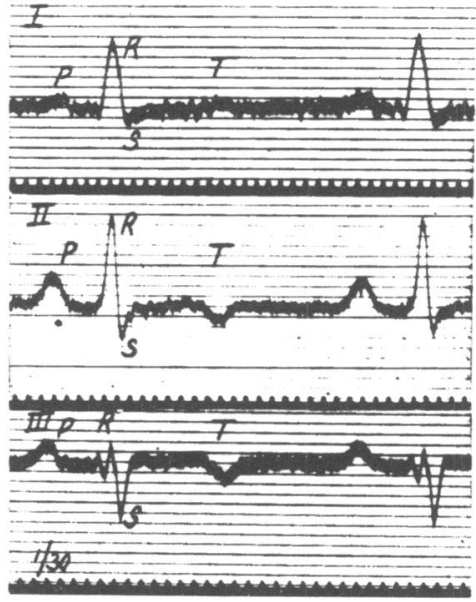

Fig. 90.

Fig. 89. Curves taken from the three leads in a case of aortic disease during a febrile attack. They show defective conduction along the right division of the $A \cdot V$ bundle.

Fig. 90. Curves from the same patient, taken a day later and while fever was subsiding. The ventricular portions of the curves have changed-profoundly ; there is now no evidence of bundle defect; but of relative preponderance of the left ventricle.

Figure 12. ECGs from a patient with aortic disease taken within one day of each other. Fig. 89 is labelled as RBBB and Fig. 90 as left ventricular preponderence. (From Lewis, op. cit., footnote 14.)

${ }^{20}$ B.S. Oppenheimer and Harold E.B. Pardee, 'The site of cardiac lesion in two instances of intraventricular heart block, Proc. Soc. exper. Biol. Med., 1920, 17: 177-179. 


\section{The history of bundle branch block}

E.P. Carter ${ }^{21}$ reported on the clinical features of twenty-two cases seen in Lewis's department at University College Hospital Medical School, twenty-one of whom had what was diagnosed as RBBB. He wrote: "It is a remarkable fact that eight patients have well developed aortic valve lesions [which] cannot be regarded as purely accidental. Yet the association meets with no very plausible explanation .... Lesions of the aortic valve would be expected a priori in association with lesions involving the conductivity of the left branch. Nevertheless this association does not occur." One might have thought that the weight of the evidence would have prevailed at this point and have led to a revision of the answer, but it was not to be, and Carter stuck to his conclusion: "Considering the evidence as a whole, there can be little doubt that the curves supposed to present human levocardiogram and dextrocardiogram, are respectively due to defective conduction in the right and in the left divisions of the bundle. The strongest reason for regarding the human curves as representing bundle branch defects is still their comparison with those obtained experimentally." No wonder, then, that Einthoven ${ }^{22}$ in a letter to Lewis in 1918, wrote, "Your comparison of the electrocardiogram from a patient suffering from aortic disease with a levogram indicating a right bundle branch lesion is very interesting. I fear that it will sometimes be difficult to decide whether the patient suffers from left ventricle preponderance or from right bundle branch lesion". Rothberger and Winterberg had similar doubts, and they wrote, "Our own clinical experience showed us that the electrocardiogram in aortic regurgitation in lead III resembles the pictures of a left ventricular extrasystole which equals right bundle branch block. This combination seems unlikely since we could not understand how aortic regurgitation should cause damage to the right bundle." Einthoven's words were echoed almost exactly by Wilson and Herrmann, ${ }^{23}$ when they re-studied the problem in 1920 . They wrote, "No sharp line can be drawn, therefore, between the curves of left ventricular preponderance and those of right bundle branch block, and the interpretation of many aberrant electrocardiograms consequently remains doubtful." They also showed that Lewis had erred in stating that the $T$ wave was upright in lead I with preponderance but negative giving a diphasic curve with block. At least half of their preponderance cases had a diphasic lead I. However, they upheld the Lewis nomenclature and defended his work from the criticism of Fahr. They were especially impressed by Eppinger and Stoerk's paper. Wilson and Herrmann also produced experimental branch block in dogs and it is interesting to compare their results with previous work and examine it in the light of what was later accepted. The electrocardiographic lead used by Eppinger and Rothberger was one from oesophagus to anus and its position in the Einthoven triangle indicates that it would yield complexes in between the limb leads II and III. Lewis and also Wilson and Herrmann used all three limb leads. The especial feature in the experimentally produced block in dog and monkey that led all those workers astray was deep

\footnotetext{
${ }^{21}$ Edward Perkins Carter, 'Clinical observations on defective conduction in the branches of the auriculo-ventricular bundle' Arch. int. Med., 1914, 13: 803-840.

22 Willem Einthoven, quoted by H.A. Snellen, Two pioneers of electrocardiography. The correspondence between Einthoven and Lewis from 1908-1926, Rotterdam, Donker, 1983.

${ }^{23}$ Frank N. Wilson and G.R. Herrmann, 'Bundle branch block and arborization block', Arch. int. Med., 1920, 26: 153-191.
} 


\section{A. Hollman}

negativity in leads II and III when the right branch was interrupted. This strong left axis deviation looks so like human left branch block that it sealed the case for them and must have closed off alternative explanations, aided by the rarity in their experience of human right branch block-up to 1916 , Lewis had only one such case. If one looks at Wilson and Herrmann's illustration (fig. 13) but examines lead I only, it is at once obvious that the pattern of the deflections with canine branch block is the same as in human beings—namely, a broad $R$ wave with left block and a broad $S$ wave with right block.

It is still by no means clear why leads II and III gave these "misleading" results-negative in right block and positive in left block when they "should" have been in the reverse direction. It has been said that the vertical position of the dog heart is the responsible factor, but this could not possibly give rise to strong left axis deviation. Perhaps the experimental technique had something to do with it, but even this explanation is unlikely because in one dog Lewis repeated the tracings after the chest had been closed and all air removed from the pleural cavities, and showed that the form of the complexes was unaltered compared to those obtained when the chest was open.

A
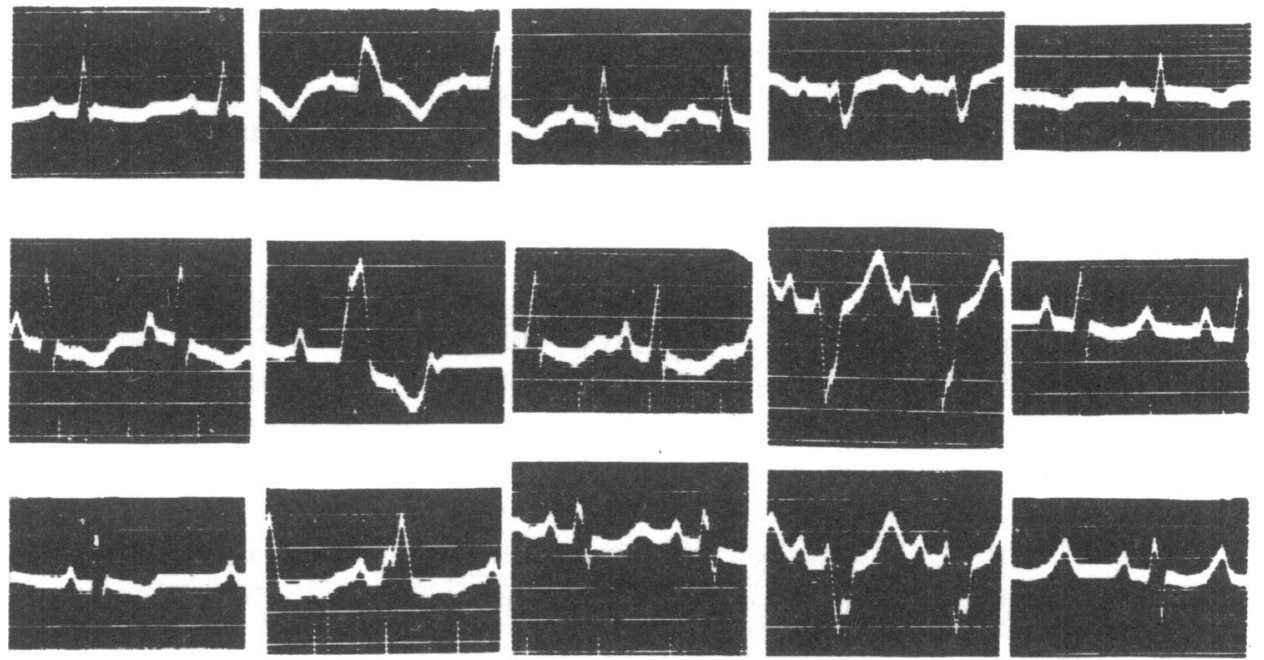

Fig. 7 . Fixperiment 7. A.-Control curves. B.-Left branch block. ('. Recovery.
I).- Right hranch block. E. Recovery.

Figure 13. Wilson and Herrmann's illustration of experimental BBB in one dog, showing, as in Lewis's experiments (Fig. 5 and 6 above), that lead I resembles human BBB whilst leads II and III do not. This experiment is very elegant because the ECGs are all from the same dog in whom transient block was produced first in the left and then in the right bundle branch. (From Wilson and Herrmann, op. cit., footnote 23.) 


\title{
The history of bundle branch block
}

It is in Fahr's 1920 paper $^{24}$ that we find the correct interpretation of human bundle branch block. Having worked with Einthoven, he was very well acquainted with the postulate that one could determine the direction and magnitude of the potential difference in the ventricles by a trigonometric method based on the Einthoven triangle, i.e. the triangle formed by leads I, II, and III. Very important in the validity of Fahr's conclusion-dismissed by Wilson and Herrmann as "arrived at from theoretic considerations"-is the fact that he showed by cadaver experiments that Einthoven's schema of the equilateral triangle was accurate to \pm 10 degrees. He did this by putting battery operated electrodes into varying positions in the cadaver heart, working out the angle of the potential difference by two string galvanometers connected to leads I and II, and comparing the derived angle with the observed one. In addition, his results were worked out from simultaneous positions in the ventricular complex of human electrocardiograms both normal and abnormal, and in this respect too were certainly not merely theoretical. Therefore, by plotting the moment-to-moment spread of the excitation wave through the ventricular mass he was able to demonstrate the changes that occurred with ventricular hypertrophy (fig. 14) and with bundle branch block (not illustrated). He wrote:

\begin{abstract}
A high RI and deep SIII means left bundle branch block, for the vectors show that the right heart is negative first and that as the left heart becomes negative the right sided preponderance is neutralised and the resultant approaches zero. Vice versa, a high RIII and deep SI in bundle branch block indicates right bundle lesion for the construction of the direction of the potential difference in the heart shows that the left side is negative first and the vector is swung toward the right about 0.05 or 0.06 seconds after the beginning of the electrocardiogram. The diagnosis of right and left bundle branch lesion as commonly made is probably wrong.
\end{abstract}

Now it is remarkable that Lewis had done exactly that same piece of work, with the same results but with a different conclusion! His diagrams (fig. 9) show that the latest activation of the ventricles occurs at an axis of $-26^{\circ}$ (left axis deviation) with what he chose to call right branch block, and at an axis of $-170^{\circ}$ (extreme right axis deviation) with left branch block. It is difficult to understand how he explained these results in the way he did. The reference to Fahr's paper is given in Lewis's The mechanism and graphic registration of the heart beat. Of the 1003 references, it is one of fourteen which lack comment in the text.

Experimental division of a bundle branch means that the ventricle concerned has to receive its excitatory impulses from the other ventricle via the musculature of the septum, and it was quickly realized by Rothberger and Winterberg and by Lewis that a very similar situation existed with ventricular extrasystoles. If, for example, the right ventricle was stimulated, then it contracted at once, but the left ventricle was delayed in its contraction because the impulse had to pass comparatively slowly through the septal muscle. Thus, a right ventricular extrasystole with its late activation of the left ventricle gave the same pattern as LBBB, and vice versa.

Lewis used his beautiful technique of epicardial mapping in the dog to show the precise time relations of right and left ventricular activation with bundle branch

\footnotetext{
${ }^{24}$ George Fahr, 'An analysis of the spread of the excitation wave in the human ventricle', ibid., 1920. 25: 146-173.
} 


\section{A. Hollman}

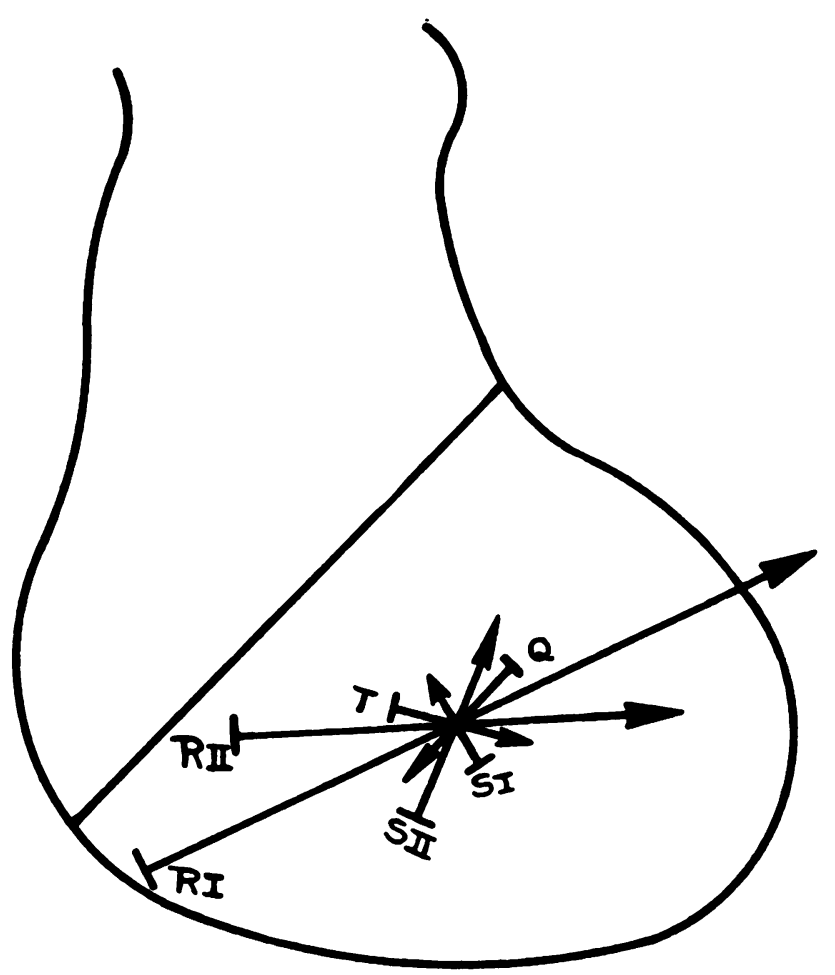

Fig. 8.-Orthodiagram of heart with predominating left ventricular enlargement with vectors of potential corresponding to various points on electrocardiogram.

Figure 14. Fig. 8 from Fahr's correct interpretation of BBB, showing his method of illustrating the vectors of potential (electrical axes) of the $Q, R, S$, and $T$ waves. (From Fahr, op. cit., footnote 24.)

block and with ventricular extrasystoles. Hoffmann in $1914^{25}$ was the first to study the experimental production of extrasystoles in man by direct stimulation of the heart. His patient had undergone rib resection on the left and the heart was covered only by soft tissues. He stimulated the left ventricle with galvanic current and with a percussion hammer, and the resulting ECG showed the pattern of RBBB which was the opposite to what would have been expected by contemporary opinions. Oppenheimer and Stewart ${ }^{26}$ had a similar patient in 1926, who exhibited himself as "The Human Heart Wonder". They purported to record stimulated extrasystoles from both ventricles, but it is doubtful if they did so. They, like others before them, were influenced by lead III, and they concluded that the terminology in present use should be retained. Einthoven ${ }^{27}$ had a remarkable case of a man whose sternum had been surgically removed and in whom "the heart was as good as naked and covered

\footnotetext{
${ }^{25}$ August Hoffmann, Die Elektrographie als Untersuchungen des Herzens und ihre Ergebnisse, Wisbaden, J.F. Bergmann, 1914.

${ }^{26}$ B.S. Oppenheimer and H.J. Stewart, 'Dependence of the form of the electrocardiogram upon the site of mechanical stimulation of the human ventricles', J. clin. Invest., 1926, 3: 593-612.

${ }^{27}$ Einthoven, op. cit., note 7 above, p. 109.
} 


\section{The history of bundle branch block}

only by a thin layer of skin". Light tapping over the heart area would produce a ventricular extrasystole, and Einthoven correctly surmised that this must originate in the right ventricle. But the limb lead pattern of these induced right ventricular extrasystoles was interpreted as being that of (to him) left branch block-when, in fact, the $S$ wave in lead $I$ is a small sharp deflection not at all like that of what we call RBBB (fig. 15).

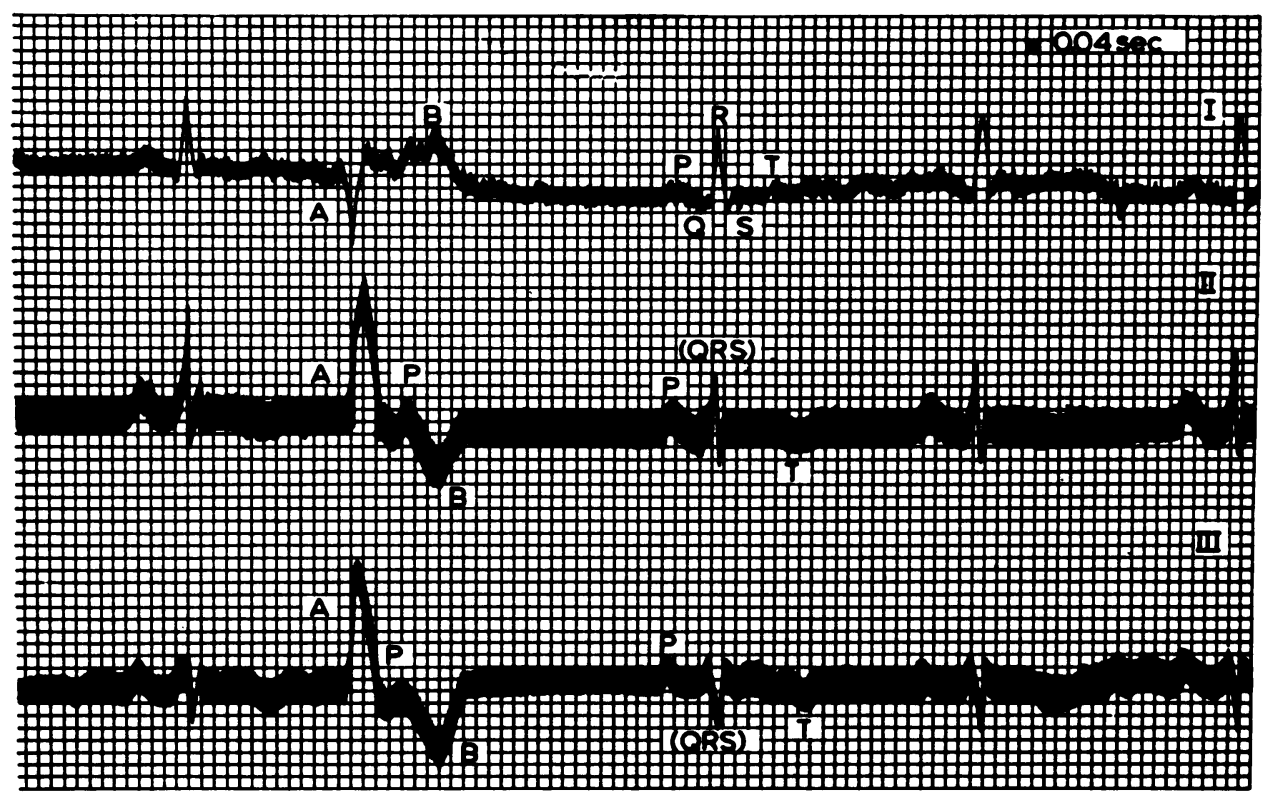

Figure 15. Einthoven's experimental production in man of a right ventricular extrasystole which he called a "pure dextrogram", i.e. to him the pattern of LBBB. (From Einthoven, op. cit., footnote 7.)

That the induced extrasystole did probably originate in the outflow tract of the right ventricle is shown by the similarity of Einthoven's tracings to those of Lenègre and Maurice ${ }^{28}$ who initiated a new era of cardiac electrophysiology in 1945 when they recorded the first intra-cardiac electrograms in man. Using an electrode catheter in the right ventricle with simultaneous recording of the limb leads, they were able to demonstrate the pattern of RBBB as seen in a cavity recording and also that of right ventricular extrasystoles. They show, in fact, two different limb lead patterns of such extrasystoles with similar but not identical cavity recordings. One pattern is the expected typical LBBB but the other is remarkably similar to that of Einthoven (fig. 16) ${ }^{29}$ But the promise offered by this line of enquiry was too good to drop, and in 1930, another surgical patient presented a rare opportunity to Barker,

${ }^{28} \mathrm{~J}$. Lenègre and $\mathrm{P}$. Maurice, 'De quelques résultats obtenus par la dérivation directe intracavitaire des courants électriques de l'oreillette et du ventricule droit', Arch. Mal. Coeur., 1945, 38: 298-302.

${ }^{29}$ Phyllis Holt et al., 'Ventricular arrhythmias. A guide to their localization', Br. Heart J., 1985, 53: 417-430. Dr Paul Curry has kindly scrutinized the Einthoven ECG in the light of his recent work. He considers that in all probability the extrasystole arose in the anterior right ventricular outflow tract. 


\section{A. Hollman}

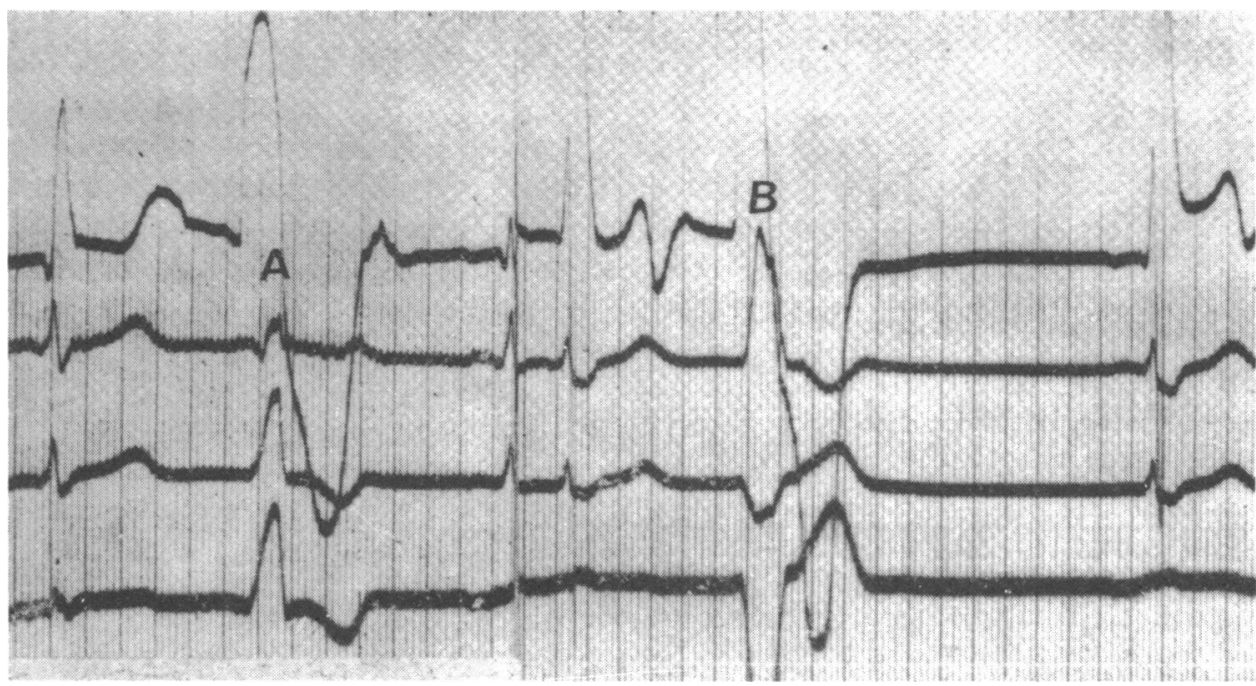

Figure 16. Fig. 2 of Lenègre and Maurice (op. cit., footnote 28). Top trace is the right ventricular cavity electrogram and underneath it are the three limb leads. The R.V. extrasystole at A is similar to that in Einthoven's experiment (Fig. 15 above). The one at B shows the more typical LBBB configuration.

Macleod, and Alexander, ${ }^{30}$ working in Wilson's department at Ann Arbor. The patient, a man of thirty, underwent surgical drainage of a septic pericardial effusion with resection of the left fifth and sixth costal cartilages. Post-operatively a considerable portion of the anterior diaphragmatic and apical surfaces of the heart could be seen through this opening. Using a flexible silver wire electrode they were able to record electrocardiograms from the right and left ventricles and their first enquiry was to study the spread of the excitatory process and to confirm in man the results which Lewis and Rothschild had obtained in the dog. Then they proceeded to record the limb leads simultaneously, using three string galvanometers, and to induce extrasystoles by electrical stimulation of the ventricles. They showed that stimulation of the left ventricle gave a downward chief deflection in lead I whilst a premature contraction of the right ventricle yielded an upward deflection in this lead, and concluded that "The clinical electrocardiograms at present ascribed to block in the right branch of the His bundle indicate block in the left branch and vice versa". Sadly, they were less than generous to Fahr, for they referred to his work only in a dismissive footnote, which read: "This view was advanced some years ago by Fahr, as a result of theoretical considerations".

In 1916, Mann had had the ingenious and novel idea of constructing a diagram of the electrical activity of the heart by fusing all three limb leads into the single curve from which they are derived, and he called this a "monocardiogram". It is, in fact, a hand-drawn vectorcardiogram. His first paper in 1920 showed vector loops with

\footnotetext{
${ }^{30}$ Paul S. Barker, A. Gerrard Macleod, and John Alexander, 'The excitatory process observed in the exposed human heart', Amer. Heart J., 1930, 5: 720-742.
} 


\section{The history of bundle branch block}

extrasystoles though not with bundle branch block. In his second paper ${ }^{31}$ in 1931, however, he said that "By 1917 these monocardiograph studies, supported by their correlation with numerous post mortem observations seemed sufficiently conclusive to justify routinely reporting the localization of bundle branch block in a manner opposite to the published interpretation of Lewis." Like Carter, he had been impressed by finding severe left ventricular disease in what Lewis called right branch block. This paper contains monocardiograms drawn from his own patients and also from Lewis's published ECGs in BBB. However, the scientific rigour of the paper falls far short of present-day standards, and two points may be made about it. First, he depicted the limb lead patterns on the sides of Einthoven's triangle with the wrong polarity so that he obtained right axis deviation with LBBB. Second, his own case allegedly showing RBBB was manifestly a case of LBBB in whom the wrong connexions had been made to the galvanometer (probably the right arm and left leg leads were reversed)! One can only conclude that Mann got the right answer from the clinico-pathological correlations and not from his monocardiograms. So his last sentence is really ironic in its homily: "Old errors cling stubbornly and it is at times necessary to remind ourselves that while truth may be a bitter pill it is a good physic."

The final chapter in this saga was written by Wilson, Macleod, and Barker ${ }^{32}$ in 1932. Their work is notable because of the use of multiple precordial leads. The first stage was to produce bundle branch block in the dog, but instead of recording direct epicardial leads, the surface of the heart was covered with a pad of gauze soaked in saline and an exploring electrode placed on it with the other electrode on the left leg. They termed this a semidirect lead. Their recordings showed that a lead close to the surface of the ventricle whose bundle had been cut yielded a late deflection. The second stage was to simulate this work in man by making recordings from four or five small copper disks which were placed on the chest wall at sites ranging from the right fourth intercostal space near the sternum to the sixth space in the anterior axillary line, with the indifferent electrode on the left leg. The results were similar to those obtained in the dog, and the authors concluded that "The common type of bundle branch block is left branch block, the rare type, right branch block." In a comment on this paper, Macleod later wrote, ${ }^{33}$ "Sir Thomas Lewis, when he heard of our results, agreed that the evidence was sound and stated that his indirect evidence should not stand in the way of our direct observations. His approval, I believe, meant more to Frank than any other."

However Lewis himself did not hasten to acknowledge the correction in his writings. In the sixth edition of Clinical electrocardiography, published in 1937, he labelled the tracings as 1st type and 2nd type and stated in a footnote, "which of these two types represents the human levogram and which the dextrogram has developed into a matter of debate; I therefore leave the curves unidentified with right or left ventricle.... Actually it is a matter of little practical consequence to which ventricle

\footnotetext{
${ }^{31}$ Hubert Mann, 'Interpretation of bundle-branch block by means of the monocardiogram', ibid., 1931, 6: $447-457$.

${ }^{32}$ Frank N. Wilson, A Gerrard Macleod, and Paul S. Barker, 'The order of ventricular excitation in human bundle branch block', ibid., 1932, 7: 305-330.

${ }^{33}$ F. D. Johnston and E. Lepeschkin (editors), Selected papers of Dr. Frank N. Wilson, Ann Arbor, J.W. Edwards, 1954.
} 


\section{A. Hollman}

the beats are assigned." In the third edition of Diseases of the heart (1942), a figure showing left block is labelled "the common type of bundle branch block". But in Electrocardiography and clinical disorders of the heart beat, probably written in 1944 and published in 1949, he used exactly the same figures as in 1913 (fig. 17) but labelled them as left (1st type) and right (2nd type).

The most remarkable contribution to this "matter of debate" was that of Kountz in $1933,{ }^{34}$ who developed a technique, which included coronary perfusion, for reviving human hearts after death. In 48 out of 127 studied he was able to make the heart contract regularly for at least two hours. In some of them, he sectioned either the right or left bundle branch and recorded the ECG from the limb leads. The results showed that George Fahr's 1920 conclusions were correct. Kountz also recorded four different types of extrasystoles by electrical stimulation of various regions of the ventricles. In respect of Einthoven' $\mathrm{s}^{22}$ experiment, it is intensely interesting to find that stimulation of the conus of the right ventricle gave upright deflections in all three leads whilst stimulating the right ventricle anywhere else gave an upright deflection in lead I and a downward deflection in lead II.

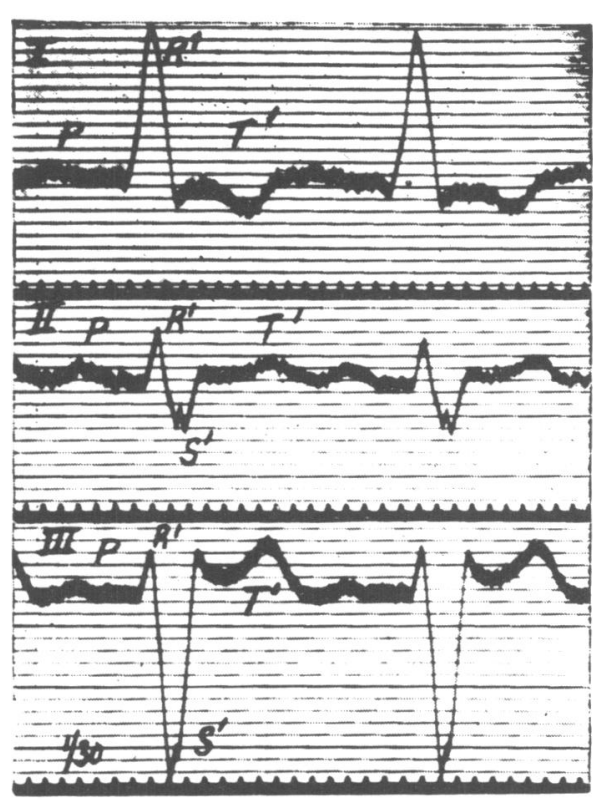

LEVOGRAMS.

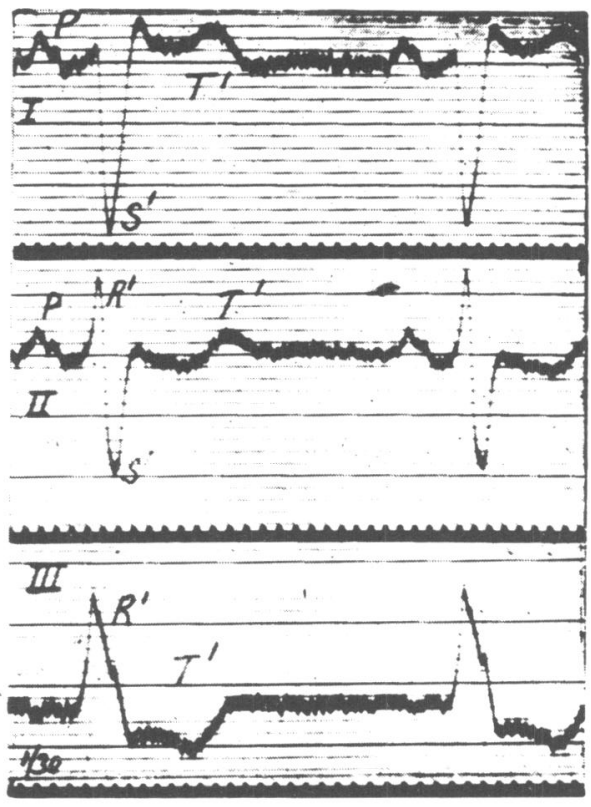

DeXtrograms.

Figure 17. This figure was used unaltered save for the captions in all editions of Lewis's Clinical electrocardiography. This one is from the 1913 edition with what he regarded as RBBB (levogram) on the left, and LBBB (dextrogram) on the right.

\section{ACKNOWLEDGEMENTS}

I am much indebted to Dr Meika Dux, who has made long and careful translations for me from the German literature, and to Dr Dennis Krikler for his very useful help and advice.

${ }^{34}$ William B. Kountz, 'Revival of human hearts', Ann. int. Med., 1937, 10: 330-336. 